\title{
Marine Heat as a Renewable Energy Source
}

\author{
Wayan Suparta \\ ScienceTech and Education Concultant \\ Sleman, Yogyakarta 55282, Indonesia \\ drwaynesparta@gmail.com
}

Received 13 February 2020, Revised 20 February 2020, Accepted 8 March 2020

\begin{abstract}
The ocean, which covers two-thirds of the land surface, receives heat from the sun's rays. Ocean water also receives heat that comes from geothermal heat, which is magma located under the seafloor. Ocean surface temperatures are warmest near the equator, with temperatures from $25^{\circ} \mathrm{C}$ to $33^{\circ} \mathrm{C}$ between 0 degrees and 20 degrees north and south latitude. This temperature difference can be utilized to run the driving machine based on the thermodynamic principle. A technology called Ocean Thermal Energy Conversion (OTEC) is capable of converting the temperature difference into electrical energy. OTEC is a power plant by utilizing the difference in the temperature of seawater on the surface and the temperature of deep seawater. This paper briefly overviews of how ocean heat can be utilized as a renewable energy source to produce electrical energy. The development and exploitation of renewable marine energy in the future is feasible and this will involve multidisciplinary fields such as robotics and informatics.
\end{abstract}

Keywords: Marine energy, Ocean surface temperatures, Ocean Thermal Energy Conversion (OTEC), Renewable energy

\section{INTRODUCTION}

Renewable energy is an energy source that comes from natural resources that are continuously and always available. Renewable energy will replace fossil energy which will eventually become extinct or exhausted like petroleum, natural gas, and coal. These energy resources can be developed and carried out safely and do not threaten the life of a marine. Such as the thermal energy of seawater temperature becomes electrical energy using the warm water temperature cycle with sea temperature. The utilization of geothermal energy as a renewable energy source produces electrical energy for pumps, turbines, and generators.

Marine energy resources are renewable energy sources originating from the sea and Indonesian waters. Indonesia with an archipelagic country whose territory is mostly sea, strait, and bay is a potential as a source of marine energy. The sea waters on Eastern and Western Islands or outside islands of the regions in Indonesia that is passed by the equator where this area produces water temperature and air temperature. Some marine energy resources, such as tidal energy, sea waves, ocean currents (underwater currents) and ocean heat energy. In Indonesia, all marine energy is still in the research stage, while in several countries such as Europe, United States, Canada, Japan, Korea, India, and Africa, these energies have been developed. From how renewable energy in Indonesia is developed, a technology so-called Ocean Thermal Energy Conversion (OTEC) is adapted. OTEC is a clean marine where the process can produce electricity by using the temperature difference between deep cold ocean water and warm tropical surface waters. This technology was first suggested in 1881 by Jacques d'Arsonval and a prototype onshore energy-extracting machine has been built in 1926 by his student, Georges Claude (Woodford, 2018).

The potential of seawater energy is not widely known by the public at large. In this case, many developed countries conduct research and development of new renewable energy potential in order to produce electricity. Perdana and Karmen (2012) conducted a study of sea heat distribution using OTEC, namely the Northern Waters of Bali, where they found a sea surface temperature of $30.30^{\circ} \mathrm{C}$, and at a depth of $600 \mathrm{~m}$ the temperature reached $6.40^{\circ} \mathrm{C}$ with a Carnot efficiency of $78.8 \%$. For Banda seawaters, it producing a surface temperature of $31.20^{\circ} \mathrm{C}$, and at a depth of $600 \mathrm{~m}$, the temperature reached $7.30^{\circ} \mathrm{C}$ with a Carnot efficiency of $76.6 \%$.

This thermal energy power plant can be utilized if the temperature difference between the warm surface and cold deep seawater is required at least 77 degrees Fahrenheit $\left(25^{\circ} \mathrm{C}\right)$ to generate electricity. By applying OTEC technology on the Cuba Coast, it was produced 22 kilowatts of electricity for the first time. The largest OTEC has been built in India with a capacity of $1 \mathrm{MW}$ using a closed system. Energy from the ocean can be categorized into three types, namely wave energy, tidal energy, and the OTEC 
results (Borthwick, 2016). This study aims to briefly overviews of how ocean heat can be used as a renewable energy source to produce electrical energy. Topics that will be discussed in the study will include the calculation of power for turbine, pump, and generator.

\section{MATERIALS AND METHODS}

\section{The OTEC Principle}

It is known that the earth has a limited amount of water and mostly contains saline in the oceans. The depth of the ocean determines its salinity where ocean currents become very high in distributing heat and nutrient cycles from the poles to the equator. When connected with atmospheric currents, it will produce clouds which in turn help regulate global temperatures and distribute water vapor throughout the world. The heat distribution in the sea can be mapped as depicted in Figure 1. As indicated by yellow and red colors in the figure, clearly that Indonesia islands located in the equator line is great potential for generating electrical energy from ocean heat.

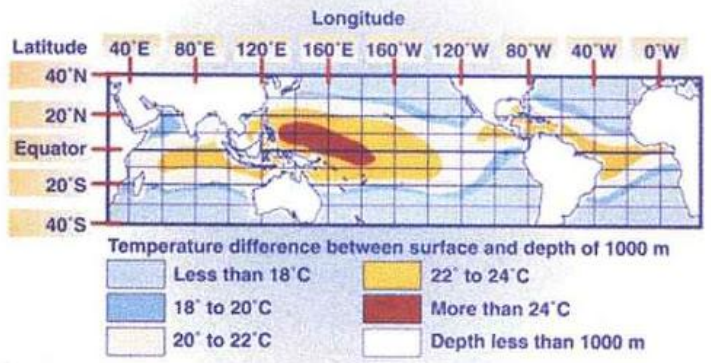

Figure 1. Map of sea heat distribution (Michaelis, 2002)

Since the OTEC technology is placed in the deep ocean (with a depth of approximately $1 \mathrm{~km}$ ), this system is equipped with various equipment so that it can work optimally in the deep sea:

1. Coldwater intake pipe is located in the deep sea.

2. Pipes where warm water enters and is located above sea level.

3. The pump functions are to pump warm water into the system.

4. The heat exchanger works to evaporate the fluid.

5. Condenser is to condense the steam.

6. The buoy system is to place OTEC equipment.

Based on the cycle used, OTEC can be divided into three types as below where each cycle will be briefly discussed (Sinuaji, 2015).
1. Closed-Cycle
2. Open-Cycle
3. Hybrid System

\section{OTEC Closed-Cycle}

Basically, OTEC system has four main components which are condenser, evaporator, turbine, generator, and pumps (Cusano et al., 2013). The OTEC schematic of a closed system can be seen as in Figure 2. The similar diagram and components can be found in the Adiputra et al. (2019) where they have proposed to develop $100 \mathrm{MW}$ OTEC power plant at Mentawai Island, Indonesia. The working fluid which uses ammonia is used to generate fluid vapor to drive turbine. When the turbine works with an efficiency of more than $80 \%$ it will produce electricity.

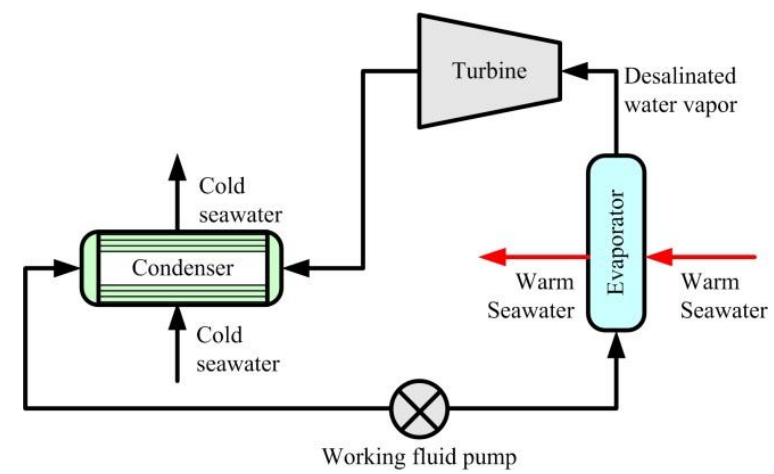

Figure 2. Simplified open-cycle OTEC process flow diagram adapted from Magagna and Uihlein (2015)

As can be seen from Figure 3, closed cycles use low boiling fluid, for example, ammonia, to turn turbines and produce electricity. Warm water at sea level is pumped to a heat exchanger (vaporizer) where boiling point boils low. The fluid that changes its form into steam will experience an increase in pressure. This high-pressure steam is then flowed into the turbine to produce electricity. The steam is then cooled again with cold water from the deep sea and condenses. Then the fluid returns to its repeated cycle.

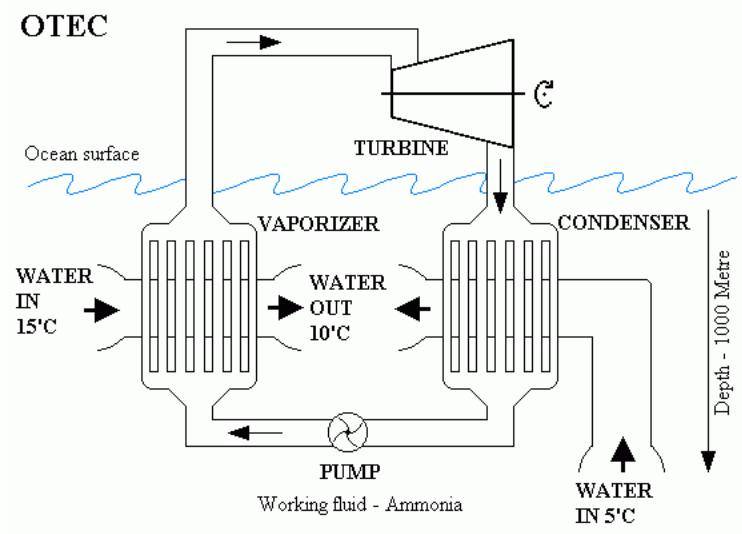

Figure 3. The principle of OTEC plant operation

\section{OTEC Open-Cycle}

The open-cycle OTEC uses warm seawater to generate electricity. When warm seawater is pumped (P) into a low-pressure container, it boils. The expanding steam drives low-pressure turbines to generate electricity. This vapor leaves saline behind the container. So this steam is almost pure water. This steam is then condensed again using cold temperatures from the seabed. Figure 4 shows the diagram of Open Cycle OTEC system. 


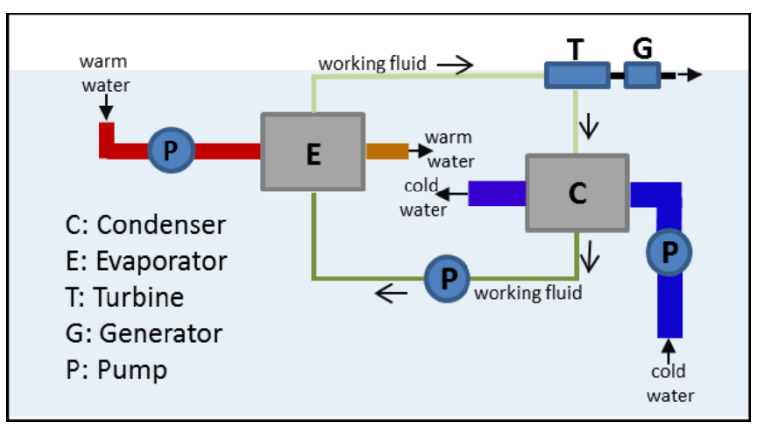

Figure 4. The schematic diagram of Open Cycle OTEC system (Cusano et al., 2013)

\section{OTEC Hybrid System}

Hybrid cycles use the advantages of open and closed-cycle systems. The hybrid cycle uses seawater which is placed in a low-pressure tank for steam. Then the steam is used to evaporate the low boiling point fluid (ammonia or others). The seawater vapor is then condensed to produce desalination fresh water.

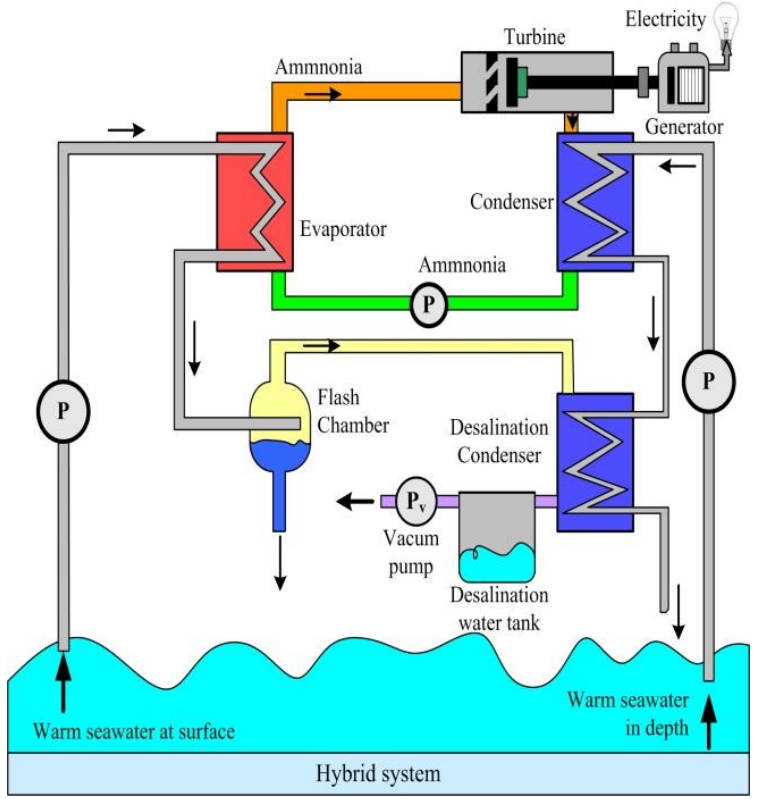

Figure 5. The schematic diagram of OTEC Hybrid system

On the whole, the OTEC works when the sea heat energy conversion uses temperature differences between warm surfaces and cold deep seawater, at least $77^{\circ} \mathrm{F}\left(25^{\circ} \mathrm{C}\right)$. This minimum temperature can be used to generate electricity. The sea absorbs heat from the Sun. Solar heat makes the surface of seawater warmer than water on the seabed. This causes seawater to circulate from the bottom to the surface. Circulation of seawater can also be used to drive turbines and produce electricity.

In the operation of OTEC, pipes will be placed in the sea which functions to suck up the heat of the sea and flow it into a heating tank to boil the working fluid. Ammonia is commonly used as a working fluid because it is volatile. The fluid vapor will then be used to drive power generation turbines. Fluid vapor is then flowed into the condenser chamber and refrigerated by using seawater with a temperature of $5^{\circ} \mathrm{C}$. The cooling water is then released back to the sea and so on, and then a repeat cycle will occur. The cycle phase of OTEC system can be summarized as in Figure 6 so-called the Rankine cycle where the working fluid evaporate in advance the temperature and pressure to drive a turbine.

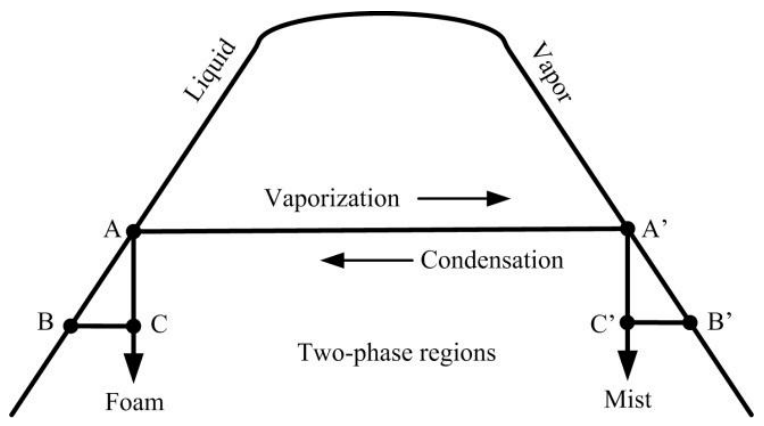

Figure 6. Rankine cycle applied in OTEC

\section{Thermodynamics Process of OTEC System}

The OTEC system relies on basic relationships between pressure $(\mathrm{P})$, temperature $(\mathrm{T})$ and volume (V) of an ideal fluid, which can be expressed with the following equation.

$$
\frac{\mathrm{P} V}{T}=n R=\text { contant }
$$

In OTEC systems, the difference in liquid temperature can be used to make an increase in inlet pressure.

A pump (see Figs. 3 and 5) is used to move liquids from one place to another through a piping media. The work done by the pump can be formulated as

$$
\mathrm{W}=V\left(P_{2}-P_{1}\right)
$$

Fluid enthalpy before pumping $\left(h_{1}\right)$ and after pumping $\left(h_{2}\right)$ where the pump efficiency is $80 \%$ can be expressed as

$$
h_{2}=h_{1}-\frac{w}{\eta}
$$

The temperature before enter to the evaporator:

$$
T_{w}=T_{c}+W\left(1-\frac{1}{\eta}\right) / C_{h}
$$

Calculation of the total power of cold and warm seawater pumps $\left(\mathrm{P}_{\mathrm{tot}}\right)$ can be formulated as

$$
P_{\text {tot }}=2\left(9.8 Q f \frac{L}{D} \frac{v^{2}}{2 g}\right)
$$

where $P_{2}$ and $P_{1}$ are pressure between cold and warm (MPa), W is the pump work $(\mathrm{J}), \mathrm{V}$ is the fluid volume $\left(\mathrm{m}^{3}\right), \eta$ is efficiency value in $\%, C_{h}$ is the specific heat of seawater, as $4.186 \mathrm{~kJ} / \mathrm{kg} \mathrm{K}, Q$ is the water flow rate $\left(\mathrm{m}^{3}\right), f$ is a friction factor, $L$ is the 
pipe length, $D$ is the pipe diameter, $v$ is the water velocity in a pipe $(\mathrm{m} / \mathrm{s}), g$ is Earth's gravitational acceleration $\left(\mathrm{m} / \mathrm{s}^{2}\right)$, and $T_{w}$ and $T_{c}$ are temperature at the surface and deep seawaters, respectively. Both $T_{c}$ and $T_{w}$ are in $\mathrm{K}$.

While during the OTEC process, a standard temperature ladder is very important to get value of $\mathrm{T}_{\mathrm{w}}$ and $\mathrm{T}_{\mathrm{c}}$, respectively. Figure 7 shows the model of temperature ladder for calculation of electrical power.

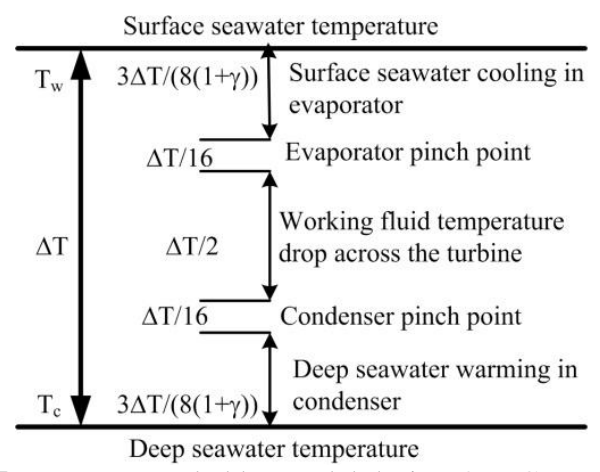

Fig. 7. Temperature ladder model during OTEC process as proposed by Nihous (2007)

From Fig. 7, the gross electrical power $P_{g}$ in OTEC process can be written as

$$
P_{g}=\frac{3 \rho C_{h} Q_{c w} \gamma \varepsilon_{t b}(\Delta \mathrm{T})^{2}}{16(1+\gamma) T_{w}}
$$

where $\rho$ is the density of seawater in $\mathrm{kg} / \mathrm{m}^{3}, Q_{c w}$ is the cold water flow rate in $\mathrm{m}^{3}, \gamma$ is the ratio between warm water and cold water flow rate, $\varepsilon_{t b}$ is the turbine generator efficiency, $\Delta T$ is the temperature difference between warm water and cold water, and $T_{w}$ is the temperature of warm surface water. Both $\Delta T$ and $T_{w}$ are in $\mathrm{K}$.

\section{RESULTS AND DISCUSSION}

This study uses seawater temperature data on the surface and at depths of up to 700 meters obtained from WOA (World Ocean Atlas) 2013 for the period 1955-2012. The data can be downloaded from www.argodatamgt.org. The data to be used comes from Argo Float Data. Argo Float is a global array of data with more than 3,000 data profiles for temperatures and salinity at an altitude of 2,000 m from the sea. Figure 8 shows the plot of surface temperature of the sea depth for the outsider of Natuna Islands.

The data processing steps are as follows:

1. Open data with ODV (Ocean Data View) software.

2. Convert data into spreadsheet form.

3. Calculate the difference in temperature and the value of efficiency. The temperature difference is calculated using the following formula:

$$
\Delta T=T_{w}-T_{c}
$$

where:

$\Delta T=$ temperature difference;

$T_{w}=$ surface seawater temperature of 0 meter (can be 26 to $30^{\circ} \mathrm{C}$ );

$T_{c}=$ depth of seawater (e.g., 700 meters);

Efficiency values can be calculated using the following formula:

$$
\eta=1-\frac{T_{c}}{T_{w}} \times 100 \%
$$

This efficiency is the same as the efficiency on the Carnot Engine. Efficiency is the ratio of energy or work in the system to the energy input into the system.

4. Get the results of the maximum and minimum efficiency values. Note that velocity of seawater transport through the working fluid is varied from 2 to $6 \mathrm{~m} / \mathrm{s}$ with an increment of $0.5 \mathrm{~m} / \mathrm{s}$. The temperature difference between surface water and water depth of $700 \mathrm{~m}$ is above $20^{\circ} \mathrm{C}$ for both dry and rainy seasons. We can also interpolate that the sea depth of $1000 \mathrm{~m}$, the sea temperature is ranging from $2^{\circ} \mathrm{C}$ to $3^{\circ} \mathrm{C}$.

5. Calculate the potential electricity that can be generated from OTEC. It is also noted that the potential electricity need to be obtained from gross power output into net power output. Usually, a lot of energy is lost especially when the power consumption needed to transport seawater to the OTEC system is very high. This situation also makes the development of OTEC expensive.

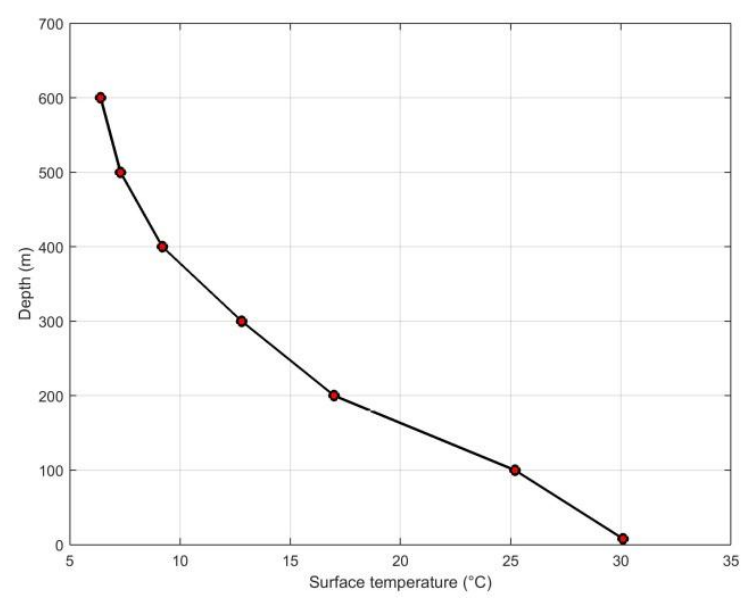

Fig. 8. The relationship between ocean surface temperatures with their depth for Natuna Islands

Based on the above method, we will calculate the potential electricity for Natuna Island. For example, the length of the coastline in the Natuna is assumed to be $800 \mathrm{~km}$ with an OTEC energy source of $7.67 \%=61.36 \mathrm{~km}$. Natuna Island is the outermost islands in the northern tip of Indonesia. If it is assumed that the distance between the $100 \mathrm{MW}$ OTEC plants being built is $10 \mathrm{~km}$, the estimated electricity potential with the OTEC power plant generated is $268.45 \mathrm{MW}$. The value of the OTEC 
factor capacity is 0.8 . Thus, the waters in the Natuna are estimated to have potential electricity with an OTEC plant of around 5,375 GWh/year. These results are listed in Table 1.

Table 1. Assumptions for OTEC potential electrical calculations

\begin{tabular}{lll}
\hline No. & Parameter & Value \\
\hline 1. & OTEC source & $61.36 \mathrm{~km}$ \\
2. & $\begin{array}{l}\text { Electricity potential } \\
\text { estimation }\end{array}$ & $613.60 \mathrm{MW}$ \\
& & $7.67 \%$ \\
3. & Efficiency & 700 meters \\
4. & Depth & 5,375 \\
5. & OTEC potential & GWh/year \\
\hline
\end{tabular}

The biggest challenge is the efficiency of the heat engines which are still below $6 \%$ because the operation is at a small temperature difference, meaning that more than $90 \%$ of the heat energy extracted from the surface of the ocean is "wasted". For the construction of generating facilities that can be done on land or with a floating platform in the middle of the sea, the further the source of energy from the coastline, of course, the cost will be even greater.

\section{CONCLUSSION}

Energy is very important for almost all activities of human life. To avoid an energy crisis due to limited energy in nature, renewable energy is needed. Renewable energy is energy derived from "sustainable natural processes", such as solar power, wind power, biological processes, and geothermal water flows. With renewable energy, it is expected that human needs for energy sources will not be reduced. There are three types of OTEC that can be used to generate power plants in a specific region, namely closed-cycle, open-cycle and hybrid system. The closed-cycle uses low boiling fluids (such as ammonia or fluorocarbon refrigerants) with the purpose of achieving high efficiency, while opencycle uses warm surface seawater as a working fluid to generate electricity, but results in low efficiency.

The territorial waters of Indonesia are ideal for developing OTEC power plants, especially on small and outer islands, because they have temperature differences between the surface and the surface that meet the criteria. It is more benefit when OTEC using the concept of land-based systems such as integrated with cooling and water systems, which are cheaper, easier, and efficient compared to off-shore systems. The investment cost for marine energy is 500 - 1,000 US dollars per $\mathrm{kW}$ while the price per $\mathrm{kWh}$ is $0.045-0.09$ US dollars. This is still expensive because energy from fossil resources is still available cheaply. Some of the recommended areas for OTEC are Western Indonesia like Natuna Islands and Eastern Indonesia, namely Morotai and West Papua. The courage to invest will open up new job opportunities and various disciplines will be involved in it such as robotics and informatics.

\section{REFERENCES}

Adiputra, R., Utsunomiya, T., Koto, J., Yasunaga, T. \& Ikegami, Y. (2019). Preliminary design of a 100 MW-net ocean thermal energy conversion (OTEC) power plant study case: Mentawai Island, Indonesia. Journal of Marine Science and Technology, doi:10.1007/s00773-019-00630-7.

Andrawina, Y. O., Sugianto, D. N. \& Alifdini, N. (2016). Initial study of potency thermal energy using OTEC (Ocean Thermal Energy Conversion) as a renewable energy for Halmahera Indonesia. IOP Conference Series: Earth and Environmental Science, doi:10.1088/1755-1315/55/1/012032.

Borthwick A. G. L. (2016). Marine renewable energy seascape. Engineering, 2 (1), 69-78. doi: 10.1016/J.ENG.2016.01.011.

Cusano, M. I., Li, Q., Obisesan, A., Urrego-Blanco, J. R. \& Wong, T. H. (2013). Coastal City and Ocean Renewable Energy: Pathway to an Eco San Andres, Vol. 3, University of Southampton.

Magagna, D. \& Uihlein, A. (2015). JRC ocean energy status report. Institute for Energy and Transport, doi:10.2790/866387

Michaelis, D. (2002). Energy Island. International OTEC Association Summer $2002 \quad$ Newsletter. http://www.solarenergyltd.net/energy\%20island.htm [Accessed on 10 February 2020].

Nihous, G. C. (2007). A preliminary assessment of ocean thermal energy conversion resources. J. Energ. Resour. ASME, 129, 10-17.

Perdana, P. Y. \& Karmen, D. (2012). Study of sea heat distribution for ocean thermal energy conversion (OTEC). Colloquium from the $R$ \& $D$ of Water Resources. https://vdocuments.site/putu-yoga-lokabeach-makalah-otec.html [Accessed on 10 February 2020].

Riyanto, S. (2017). Study of utilization of seawater potential temperature as a renewable energy source to generate electric energy. Jurnal Inovtek Polbeng, 7, 20-28.

Sinuhaji, A. R. 2015, Potential Ocean Thermal Energy Conversion (OTEC) in Bali, KnE Energy, 5-12.

Woodford, C. (2018). OTEC (ocean thermal energy conversion). https://www.explainthatstuff.com/howotec-works.html [Accessed on 9 February 2020]. 